\title{
Land Use Capability Analysis for Agricultural Land Planning in Niger
}

\author{
Tara Ippolito ${ }^{1}$, Jeffrey Herrick ${ }^{2}$, Ekwe Dossa ${ }^{3}$, Maman Garba $^{3}$, Mamadou Ouattara ${ }^{3}$, \\ Uppendra Singh ${ }^{4}$, Zachary Stewart ${ }^{5}$, P.V. Vara Prasad ${ }^{5}$, and Jason Neff ${ }^{1}$
}

${ }^{1}$ University of Colorado at Boulder

${ }^{2}$ USDA Agricultural Research Service

${ }^{3}$ INRAN

${ }^{4}$ International Fertilizer Development Center

${ }^{5}$ Kansas State University

October 30, 2020

\begin{abstract}
Smallholder agriculture is a major source of income and food for developing nations. With more frequent drought and increasing scarcity of arable land, land use planning can be used to better allocate land resources to support regional agricultural activity. To support this objective, we used the Land Capability Classification (LCC) system to map the basic limitations to agricultural use of land. The LCC is a stepwise hierarchical land assessment system that can be used to understand factors that limit land use potential. We carried out our assessment in the Dosso region of Niger. Using two public soil data sets, Food and Agriculture Organization Harmonized World Soil Database and International Soil Reference and Information Center (ISRIC) SoilGrids, and a modified version of the LCC, we developed $250 \mathrm{~m}$ gridded maps of LCC values across the region. To validate the LCC maps, we interpolated soil physical data from 1308 field sites in the Dosso region and created LCC maps based on these interpolated data. We find that across the region, land is very severely limited for agricultural use by available water-holding capacity (AWC) which limits dry season agricultural potential, especially without irrigation, and requires more frequent irrigation where supplemental water is available. If the AWC limitation is removed in the LCC algorithm (i.e. simulating the use of sufficient irrigation or a much higher and more evenly distributed rainfall than is received by the Dosso region), the dominant regional limitations become less severe and more spatially varied.
\end{abstract}

\section{Hosted file}

Manuscript_Tara_Ippolito (1).pdf available at https://authorea.com/users/371434/articles/ 489779-land-use-capability-analysis-for-agricultural-land-planning-in-niger 

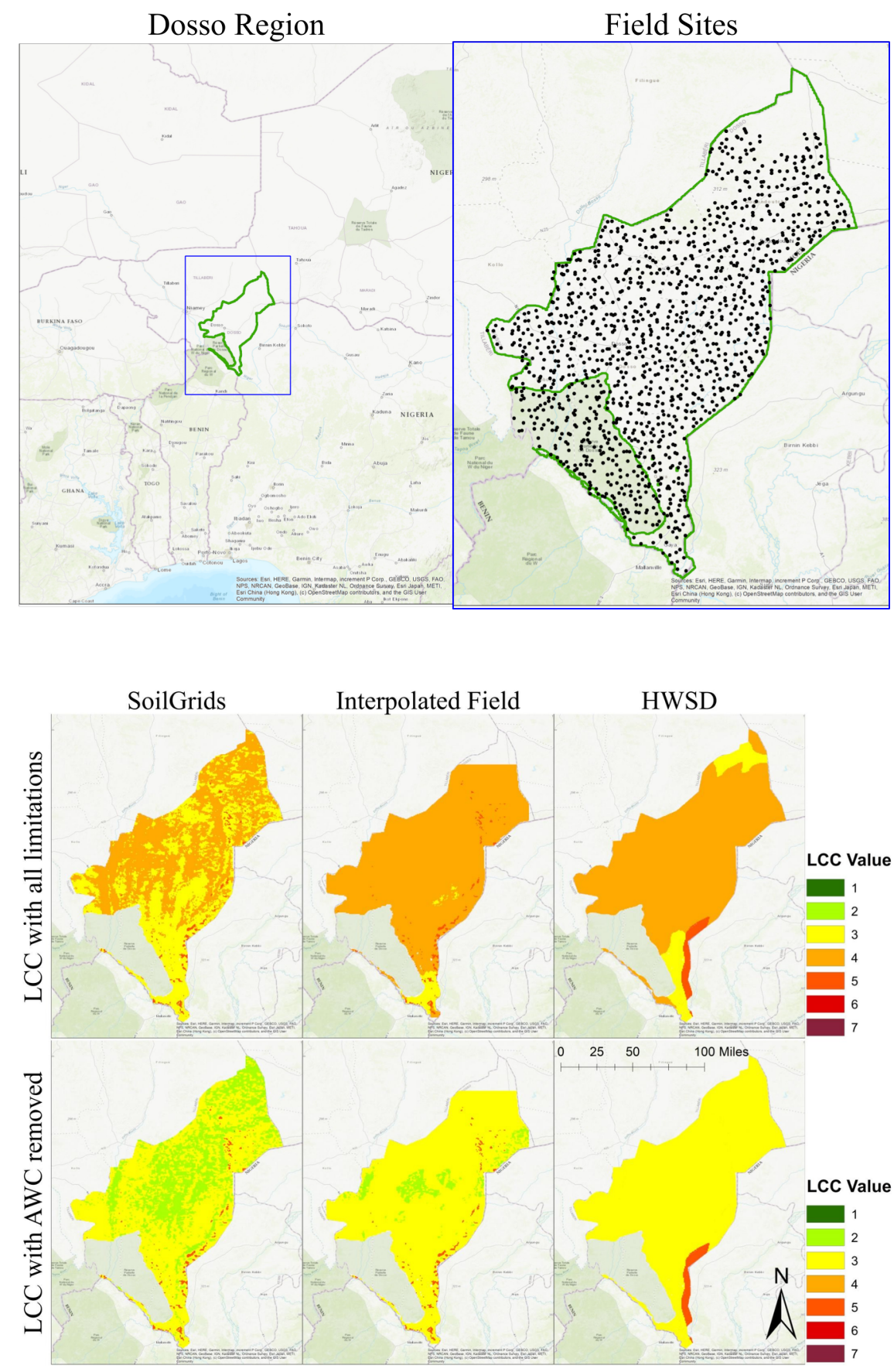


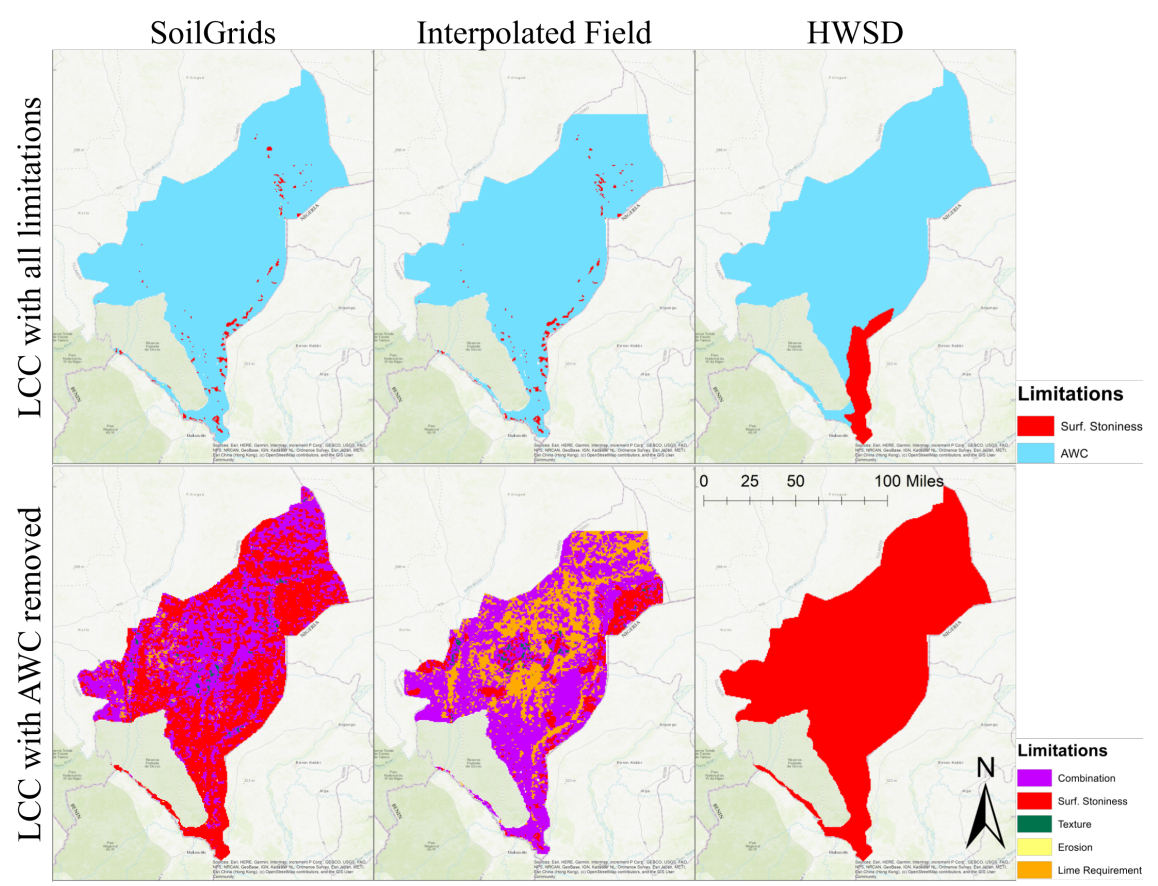

